\title{
sciendo \\ CONCEPT OF METHODOLOGY FOR SUPPORTING INFORMATION AND TECHNICAL RESOURCES MANAGEMENT IN CRISIS SITUATIONS
}

doi:10.2478/mape-2018-0044

Date of submission of the article to the Editor: 04/2018

Date of acceptance of the article by the Editor: 07/2018

MAPE 2018, volume 1, issue 1, pp. 345-351

\author{
Jan Kaźmierczak \\ Silesian University of Technology, Poland
}

Jerzy Uchroński

Police Central Bureau of Investigation, Poland

\begin{abstract}
The article presents a concept of the methodology of managing information and technical resources related to carrying on the activities and actions described in the first part of the study, and the majority of legally determined actions resulting from the emergence of a crisis situation. As a research area, a special public utility object was chosen, namely a civil airport. The crisis situation that occurred at the airport requires the involvement of many services that aim to implement actions aimed at solving it. The process of the above-mentioned activities, covers formal, organizational and technical aspects. These aspects are briefly shown in the second part of the article. In the third part, special attention was paid to collecting information flows on the crisis situation. On the basis of the research, it was pointed out that the diversity of notification systems, both in the aspect of the available information resources and technical infra-structure, makes the information exchange process disturbed, which may have a significant impact on the time and manner of resolving the crisis situation. The authors in the article point out a possible way to solve this problem by unifying the system of informing all the services involved in activities in a crisis situation. The final part of the article attempts to present a methodology, based on the idea of creating templates of actions, activities and processes, the use of which for crisis management will allow involved bodies to improve the effectiveness of services in crisis conditions, especially in the area of making decisions based on available information.
\end{abstract}

Keywords: crisis situation, airport, information, crisis staff, management, communication, template models, procedures templates

\section{INTRODUCTION}

Crisis situations in modern times are frequent and have a growing impact on the functioning of public infrastructure. Depending on their place of occurrence, such situations may cause disorganization or even paralysis of the functioning of both the infrastructure itself and social life at the level of communes, counties (pol. "powiat"), voivodships and even on the scale of the whole country. The concept of crisis, or more precisely - a crisis situation, will be used in this report in accordance with the provisions of the Act of April 26, 2007 on Crisis Management (Act on crisis management of April 26, 2007).

In particular, the subject of the considerations presented below are the aspects specified in the abovementioned Act (Art.2) "the activities of organs of public administration, as an element of national security, which relies on crisis prevention, preparation for taking over control of them through planned activities, responding in case of crisis removing their effects and playback "resources and infrastructure critical", related to the need and possibilities of using information resources and technical resources. The emergency situation described above can take various forms depending on the place and the reason for its occurrence. With the development of technology, the catalog of measures that may consequently cause crisis situations is becoming more and more extensive. In addition to epidemiological threats and 
natural disasters, it is necessary to mention here crisis situations triggered in a conscious manmade manner. One should also mention here the special cause of the emergence of crisis situations for which terrorist acts should be recognized in the contemporary world and in the current geopolitical situation. Due to the threat of such attacks in a particular degree for air transport, the research task already presented in the authors' previous publications has been undertaken (e.g. (Uchroński et al., 2016)).

\section{SUBJECT AND PURPOSE OF THE RESEARCH}

Taking into account the above-mentioned assumption on limiting the scope of the research task, aimed at developing a coherent method of supporting tasks related to crisis management, in particular for a specific area of air communication, as an area of identification of specific problems through appropriately planned preliminary tests, the identification and evaluation of the emergency response system of emergency services was selected on the example of the Katowice-Pyrzowice international airport. It is a public utility object of special importance from the point of view of crisis management. Due to the international nature of the airport's operations, its vulnerability to any type of crisis situation is very high. The existing legal restrictions governing airport operations (Aviation Law Act of July 3, 2002), both in the aspect of safety in operational terms (Safety) and in the aspect of civil aviation security (Security) are designed to minimize the risk of a crisis situation, which not only affects the region but also its effects. for the whole country, causing a kind of paralysis in its functioning. Important for the considerations presented in this study is the involvement of many emergency services in the conditions of occurrence of this type of situation (Police, Fire Service, Ambulance Service, Security Service etc.). In particular, joint activities require effective coordination of the activities of these services at the level of the so-called "complex administration" (both in the province and in the county).

Moving to the detailed area of the research project presented here, it is worth noting that not all emergency services currently have adequate technical capabilities in terms of acquiring, but especially providing / receiving information / instructions important to averting the crisis. This statement concerns in particular the transmission of information between various entities involved in the management of crisis situations. The ability to provide current information directly to the services concerned and thus to ensure rapid rescue action is of vital importance to the health and life of people / victims involved in the crisis. The direct communication of services allows to limit the effects of the crisis, its spread, and the same knowledge of all services about the crisis at a given moment, may also be important for the safety of the rescue groups themselves.

The airport consists of many elements, in which the role of the human factor is strongly marked. Suitable operation of the airport requires the management entity to ensure an adequate level of security. In current research on the issue of the continuity of the airport's operation, the focus was mainly on the problem of operational readiness, i.e. the reliability of individual technical elements of the system, which constitutes the airport, together with their reliability structure and random interfering factors, for example, meteorological conditions. Among publications dealing strictly with the subject of the airport security system, it is worth pointing out the work (Gkritz et al., 2006), which indicated the need not only to ensure the proper level of airport security, but also to minimize the nuisance of this process for the passenger. The original way of meeting the expectations for security control is proposed, for example, in (Glaeser and Shapiro, 2002), showing the savings possible to achieve thanks to the so-called virtual queues.

\section{CRISIS MANAGEMENT AT THE AIRPORT}

Air transport has been subjected to a number of legal regulations, for which the Law Act (Aviation Law Act of July 3, 2002) obliges primarily so-called The airport manager. In order to understand the role of the airport manager in the functioning of the entire airport, it would be 
necessary to trace a number of national and international legal acts, from the Aviation Law to detailed implementing acts, such as even one of the basic aviation security documents i.e. NASP (National Civil Aviation Security Program, 2012). The basic element from which to get out is to define a crisis situation. The legislator attempted to define the aforementioned concept.. At NASP, it is stated that "a crisis situation is a threat to security by occurrence or the possibility of an act of unlawful interference in civil aviation".

During the current work at the airport, we meet every day with a situation that, according to applicable legal regulations, can be classified as crisis. The insufficient awareness of passengers in the field of civil aviation security has a significant role in generating such events. Apart from deliberately committed acts of unlawful interference, almost every day such cases are caused by the unconsciousness of the perpetrator of the act. Often at the airport there is a potential need to evacuate passengers from the passenger terminal due to unattended suitcases, bags or plastic bags. For security services working at the airport, such a left-over object means a potential bomb threat causing the necessity to implement special procedures of conduct related to the occurrence of this type of crisis situation. The presumption of real danger is always assumed.

In each case of a crisis situation, the so-called "Crisis team" gathering (in accordance with § 105 sec. 2 of the NASP) all services necessary to overcome the crisis situation. The basic condition for effective implementation - firstly by the crisis team (hereinafter referred to as the Team) - resulting from the existing situation of tasks is that the structure has an appropriate, up-to-date data resource and the ability to process such data for information needed to make decisions. What is needed is in particular an efficient and effective system of circulation of such information.

\section{FLOWS OF INFORMATION IN A CRISIS SITUATION AT AN AIRPORT}

Due to the number of entities participating in the Team, the first role of the system indicated above should be to maintain a certain "communication discipline". Thanks to this, decisions made by the Team should quickly reach the operational services directly involved in solving the given crisis situation.. It is also worth emphasizing that the Team also cooperates in the field of counteracting acts of unlawful interference and their effects with government administration bodies and the air traffic management authority. For this purpose, the airport manager prepares, in agreement with the Police and Border Guard and in agreement with airport users, a plan to counter the crisis situation in civil aviation. The implementation of this plan is obviously determined on the one hand by the completeness of the available information, and on the other hand - the efficiency of technical infrastructure related to communication between the participants of the discussed process.

In the event of a crisis situation, reliable and precise communication between all levels of crisis management is of key importance. After obtaining information on the act of unlawful interference occurring at the airport or on the aircraft, a series of actions interrelates and interrelates with each other:

- The management body shall immediately notify the President of the Civil Aviation Authority (hereinafter referred to as the CAA);

- The managing body of the airport shall immediately notify the CAA and the crisis management center of the territorially competent voivode, and convene a staff;

- The CAA shall notify the minister competent for transport;

The security service undertakes actions specified in the airport security program. For each of the above authorities, the information provided generates the necessity to initiate procedures specified for a given situation. For example, the Crisis Management Center sends people in the so-called the area of concentration of services medical security in the form of ambulances, the State Fire Service sends rescue and fire services, and the Police and the Border Guard are attracting additional forces necessary to secure the event. The implementation of such procedures requires effective information on their course of the subject managing the process, as well as the mutual transfer of information between the participants of this process. The 
necessity to provide immediate information also applies to the carrier/administrator of the aircraft if it is related to the crisis. The commander of such an aircraft in the event of a threat of unlawful interference shall transmit, by any available communication means, information on the threat to the air traffic management unit with which he is in contact at that moment. This in turn generates further activities of the managing entity, which:

1) provide information to the managing body of the airport, to which the aircraft is guided (after prior information transfer to the CAA;

2) transmit the information to the competent authorities of the states over whose territory this flight takes place or will take place;

3) transmit information to the services of the air defense system;

4) take action to securely end this flight.

If, however, the management body which received the information on the act of unlawful interference, operates at the airport to which the threatened aircraft is directed, this information is transferred directly to the airport's managing body.

One cannot analyze the principles of information flow during a crisis situation, apart from a specific but very important element of communication, which is communication between the management and the mass media. According to $\S 117$ NASP, manager headquarters or a person authorized by it to provide information about an act of unlawful interference with the media. Practice shows that not only passengers or employees at the airport are involved in the crisis situation, but also the families of victims of the event interested in the fate of their relatives and demanding information about their relatives and widely understood media (TV, radio, press), which in turn fighting for audience, they outdo each other in giving the latest news from the place of the crisis.

The information provided by the Team must be carefully prepared, precise and reliable in order to satisfy the curiosity of the above-mentioned people, while not introducing untried messages or information reserved for state services until the circumstances of the incident have been clarified. In order to discuss the above-mentioned needs and capabilities of the service involved in crisis situations at airports and entities responsible for managing such situations, the next part of this study focuses on the specific case of the crisis related to the terrorist act.

\section{CRISIS MANAGEMENT AT THE AIRPORT DURING A TERRORIST ACT}

For the purpose of a more detailed analysis of the factors affecting the security risk in the functioning of the airport, the threats related to terrorist acts were considered in this study. According to the "Encyclopedia Powszechna PWN", terrorism is "variously motivated, ideologically, planned and organized actions of individual people or groups, undertaken in violation of existing law in order to extort from state authorities and society specific behaviors and services, often violating the welfare of bystanders; these actions are carried out with all ruthlessness, by means of various means (psychological pressure, physical violence, the use of weapons and explosives), under the conditions of a specially given resolution and deliberately created in society anxiety.

The protection of civil aviation against acts of unlawful interference is devoted to many acts of international law, such as: Annex 17 of the Chicago Convention, the Tokyo Convention, the Hague Convention, the Montreal Convention, and the Protocol supplementing the Montreal Convention. Very large changes occurred in EU legislation this year. The entry into force of Regulation (EC) No 300 of the European Parliament and of the Council of 2008, together with supplementary rules, has partially altered European regulations in the field of civil aviation security.

The national regulations in this regard included in the Aviation Law and in the National Aviation Security Program (NASP) also apply to such crisis situations. According to Polish NASP, through a crisis situation in civil aviation - it is understood as "... a threat to security by the occurrence or possibility of an act of unlawful interference in civil aviation". The aviation authority, the airport manager as well as the institutions and companies operating on the 
airport are obliged to be fully prepared for the above-mentioned occurrence. The Airport Manager is responsible, inter alia, for: development in consultation with the Border Guard, Police and Customs Service, if it operates at the airport, security program, organize activities to protect the airport against acts of unlawful interference and supervision over these activities, managing the airport security team, specified in its regulations, conducting an ongoing assessment of the threat of the entity and its documentation, based on the guidelines of the $\mathrm{CAA}$, and preparation and implementation of measures aimed at eliminating or limiting the effects of these threats.

The manager as a coordinator of these activities works in cooperation with other services operating at the airport, in particular on the basis of the Airport Security Committee, which includes: Airport Security Guard, Border, Police, representatives of airlines operating at the airport, representatives of other operators aviation business at the airport, fire protection services. The airport, as a set of connected vessels, cannot function quite independently and one cannot make decisions affecting the functioning of the Airport without the participation of even the Duty Service, Air Traffic Service, medical rescue unit or others.

The tasks of such a team include, in particular: expressing opinions and submitting proposals to ordinances and ordinances prepared by the airport manager in the field of airport security against acts of unlawful interference, expressing opinions and submitting applications to the airport security program, assessing the airport's threat to unlawful interference and taking action to counteract these acts, expressing opinions on solutions regarding the operation of terminals in accordance with regulations in the field of civil aviation security, initiating the introduction of new solutions and procedures for check-in and security control of passengers and baggage, cargo, courier and express mail and mail, including provisions on civil aviation security, evaluation the state of cooperation managing the airport with carriers, other entities conducting aviation business, security services and Customs Service operating at a given airport, within the scope of implemented projects in the field of civil aviation security.

As the initial assumption of the exercise performed on 05 July 2016 at 10:00 am at the Katowice - Pyrzowice International Airport, a crisis situation was announced related to the disclosure in the cargo warehouse on a pallet of $16 \mathrm{~kg}$ of goods from China described very roughly. A review by the Custom was ordered with regard to the remedies. The product was in 16 packages and self-ignition occurred during sampling. The instinctively controlling person threw the burning parcel into the bucket next to it. Then there was an explosion as a result of which the customs officer and warehouseman were wounded. Both were conscious. The exercises were attended by representatives of such services as the Border Guard, Antiterrorists, State Fire Service, Police, Airport Security Service, Ambulance Service, Operational Duty. Conducted during the exercise, we have seen the initial actions taken by all services, starting with the transfer of information in the duty service of the airport bomb threat / chemical warehouse in Cargo (10:00), ending with the arrival at the Chemical Rescue Forces (12:00). Analyzing the results of the exercise, in particular, taking into account the time of taking information about the crisis situation up to the moment of arrival of appropriate response services is too long, which may significantly affect the effectiveness of neutralizing the crisis.

Existing procedures in the area of, inter alia, formal establishment and launch of the Crisis Team at the airport as well as the method of notification of individual response services, extended the immediate reaction to the existing danger. It should also be noted that in case of a crisis situation, for updating a hijacking plan, a sabotage proceeding plan, an action plan in the case of a threat of mass destruction, emergency procedures in case of unexpected highrisk situations, actions and procedures in an emergency situation - bombing, evacuation and searching of an aircraft being the object of attack or threat, as well as informing about incidents, the Airport Manager is responsible. The manager, through the services subordinate to him, as well as members of the Airport Security Committee, performs this task based on the 4 phases of crisis management: 
- PREVENTION - analysis and assessment of threats, training of security services and the whole staff working at the airport,

- PREPARATION - development and implementation of emergency response plans, development of appropriate security procedures, provision of a specialized crisis communication system, alarm system, commanding positions,

- RESPONSE - after the occurrence of a real threat, launching the alarm system, ensuring the circulation of information, undertaking preventive actions and rescue actions;

- REBUILDING - the final phase of crisis management aimed at restoring the normal functioning of the airport.

Because this is a permanent process, each time after the restoration of the normal operation of the airport after the event (exercise), its course is subjected to thorough analysis and evaluation by all participants. All elements of the course of the event and actions taken are subject to evaluation. The reconstruction process does not end with the start of check-in and aircraft operations.

In the RESPONSE phase after the occurrence of a real threat or event based on plans to counteract such situations, the airport manager calls a crisis team that conducts activities in the ANTICRISIS COORDINATION CENTER. In order such activities can take place in the "center", it must be properly prepared. Requirements to be met by the "center" intended to direct actions aimed at resolving the crisis situation are contained in Chapter 4 of the Regulation of the Council of Ministers of 31 July 2012 on the National Civil Aviation Security Program implementing the principles of aviation security. The airport manager prepares rooms: for staff, social work, negotiator's work, for translators and necessary equipment: wired and wireless communication means equipped with caller identification system, maps and plans of the airport and surrounding area, construction projects of the facilities located at the airport, radio and television equipment, interior plans for all types of aircraft operating from a given airport, copies of the airport security program and air carriers' security programs and a phone book - internal and external contacts.

\section{THE CONCEPT OF CRISIS MODELING METHODOLOGY AT THE AIRPORT}

The analysis of the activities of entities involved in the implementation of tasks related to the occurrence of crisis situations, especially at airports (airports), leads to the conclusion that activities, actions and procedures of a formal nature play an important role in the processes associated with such situations, and so; in a sense repetitive. The above statement was the base for recognizing by authors a set of needs which are concerned with the research problem (Kaźmierczak, 2016) and - consequently - the reason for the attempts to use the modeling of processes related to crisis situations to be used, the approach developed for modeling selected production processes and described, among others, in (Duda, 2004; Kühn, 2006).

According to this concept, the process model containing elements of a repetitive nature can be "composed" using the so-called process templates (PT). such an approach has been and is effectively used in supporting engineering processes using information technology. In particular, it is possible to recall the concept of "Computer-aided process planning" systems of the CAPP (El Maraghy, 1993). In literature related to production planning processes, (Duda, 2013) it is indicated that the "template" of the process should reflect both the general structure of the process and define the resources of creative knowledge.

As indicated above, also in crisis management processes we can distinguish - on the one hand - the phase of planning activities of structures, organizations and people involved in solving the crisis, on the other hand - identify the resources of knowledge/information/data necessary for the effective functioning of all entities in crisis conditions.

As an important element of the discussed concept, one should also consider the possibility of creating templates starting from elementary components of the process ("activities"), then associating such elementary templates to action templates, understood as sequences of 
actions, and finally - potentially - process templates as process associations actions that in the appropriate sequence creates the analyzed process. At the same time, such an attempt to "transfer" the discussed method from the area of production planning to the area of crisis management must take into account the significant diversification of both areas. It seems that an important element of such diversification, which the authors of this publication intend to include in further research, is the presence in the processes of crisis management of elements (activities, activities) and situations that are difficult to predict (unpredictable?). The problem to be solved is in particular the way to include such elements in the modeled process, which will also significantly affect the tasks related to the data / information / knowledge resources and the technical security of such activities.

The template-based approach can be used - as well - for modeling processes of applying various technical means (as - for instance - Unmanned Aircraft Vehicles UAV (Piechoczek et al., 2017) for the needs of crisis management.

\section{SUMMARY AND CONCLUSIONS}

The specificity of crisis situations requires taking into account in the activities carried out in connection with the crisis situation, both routine and formalized activities and activities, and thus particularly vulnerable to the use of templates, as well as "unconventional" actions and decisions. The considerations presented above constitute for the authors of this study the basis for creating a mixed crisis management model, combining "template" activities and actions with recommendations/recommendations for activities and activities that are not very susceptible or not susceptible to this form of description.

\section{REFERENCES}

"Act on crisis management" of April 26, (2007). (Polish) Journal of Laws 2007 No. 89, item 590, with later amendments.

“Aviation Law Act” of July 3, (2002). Art. 2 par. 4 (Polish) Journal of Laws of 2013, item 1393, as of 2014, item 768 with later amendments.

Duda, J . (2004). Computer Aided Assembly and process planning in the integrated product development environment. In: Proceedings of 7th Int. Conference "New Ways in Manufacturing Technology". Presov / Slovakia, 2004.

Duda, J . (2013). Development of methods for designing technological processes of machining, In: Innovation in management and production engineering; edited by R. Knosala, Publisher. Polish Society of Production Management, vol. 2, pp. $849-861$.

El Maraghy, H. A. (1993). Evolution and Future perspectives of CAPP. In: CIRP Annals-Manufacturing Technology, vol. 42, edition 2, pp. 739-751, Editor Elsevier .

Encyklopedia Powszechna PWN (2018), [online] Available at: https://encyklopedia.pwn.pl [Accessed 20 May 2018].

Gkritz, K., Nieier, D. and Mannering, F. (2006). Airport security screening and changing passenger satisfaction. Journal of Air Transport Management, 12, 213-19.

Glaeser, E.L. and Shapiro, J.M. (2002). Cities and warfare: the impact of terrorism on ur-ban form. Journal of Urban Economics, 51, 205-24.

Kaźmierczak, J. (2016). Engineering of Needs (Eon): The Role of Identifying and Analyzing Needs in Engineering and Engineering Management. DEStech Transactions on Social Science, Education and Human Science. doi: 10.12783/dtssehs/icss2016/9104.

Kühn, W. (2006). Digital Factory - Simulation enhancing the Product and Production Engineering PROCESS. Proceedings of the IEEE 2006 Winter Simulation Conference.

"National Civil Aviation Security Program", (2012). Regulation of the (Polish) Minister of Transport, Construction and Maritime Economy of July 31.

Piechoczek, E., Kaźmierczak, J. and Jafernik, H. (2017). Modelling the Use of Alternative Technical Means for Services by Piloted Flying Platforms: Presentation of a Research Project. Procedia Engineering, 182, 571 - 578. doi: 10.1016/j.proeng.2017.03.156.

Uchroński J., Mańka, A. and Kaźmierczak, J . (2016). Application of the process approach to supporting the management of information and technical resources in crisis situations. In: Proceedings of the XIII International Conference "Supporting Systems in Production Engineering", Wisła - Olomouc / Poland - Czech Republic, September 7-10, 2016. 